\title{
The shaping of rationality in science and religion
}

J Wentzel van Huyssteen

Princeton Theological Seminary

\begin{abstract}
In this paper the focus is on the extreme epistemological complexity of the relationship between religion and science as two dominant forces in our culture today. This complexity is aggravated by a seemingly conflictual postmodern, pluralist challenge to a culture that already reveals itself as decidedly empirically-minded. For theology and science a meaningful dialogue becomes possible only if both modes of reflection are willing to move away from overblown foundationalist epistemologies and, for theology at least, from the intellectual coma of fideism. The paper finally argues for a postfoundationalist epistemology where theology and science, although very different modes of reflection, do share the richness of the resources of human rationality. In so doing it attempts to answer three crucial questions: i) are there good reasons for still seeing the natural sciences as our clearest available example of rationality at work? ii) If so, does the rationality of theological reflection in any way overlap with scientific rationality? iii) Even if there are impressive overlaps between these two modes of rationality, how would the rationality of science and the rationality of religious reflection differ?
\end{abstract}

\section{INTRODUCTION}

Anyone who takes time today to reflect on the enduring but troubled 'science and religion' dialogue will inevitably find the intellectual and spiritual mood of our contemporary Western culture at the heart of this complex debate. This mood is radically pluralist and postmodern, and as such would resist any attempt to catch it in one name or one overarching description. Yet, I do believe that we have good reasons for calling our culture at least, or also, a decidedly empirical culture: a culture determined by a tradition where the sciences - especially the natural sciences - not only dominate the way we live our lives, but ultimately function as the paradigm and apex of human rationality.

* Published with the permission of Cambridge University Press. This paper was read at the Science and Religion Conference of the Royal Institute of Philosophy at the University of Warwick, UK, on March 24, 1995. 
That religion, and religious faith, are often and in many ways intellectually marginalized in this situation is by now a fact of life and as such taken more or less for granted. Many theologians, and also scientists who are believers, have of course taken on the ongoing conflict between science and religion as a special challenge to identify possible models for creative dialogue and even consonance or harmony between theology and science (cf Barbour 1990:1-30). In many ways this reflects an enduring attempt to identify religious faith as an autonomous moment in human experience which, as such, can never be completely reduced to science, or even to metaphysics or morality. On this view religion has its own integrity, with both religious belief, reflection and practice viewed as valid expressions of the religious dimension of life (cf Proudfoot 1985: xiiif).

Strong pleas for the autonomy of religious faith and experience will of course always fuel the ongoing 'religion and science' debate, but it also reinforces some important - and confusing - stereotypes that have kept alive some of the typical or 'classical' problems of this debate. The most important of these problems reveal strong contradictions and even conflict (cf Theissen 1984:4ff) between scientific thought and religious faith, and can be stated as follows:

* scientific statements are hypothetical, fallible and tentative, while statements of religious faith are dogmatic, ideological and fideistic;

* scientific thought is always open to critical evaluation, justification or falsification, while religious faith goes against the facts and often defy empirical evidence;

* scientific thought delights in critical dissent and constructive criticism, while faith more often than not depends on massive consensus and uncritical commitment;

* scientists therefore seem to base there beliefs on evidence and argument, while religious beliefs appear to be founded on 'faith' only.

It comes as no surprise that, on this view, science emerges as the great alternative to religious faith (cf Midgley 1992:139). Many of us, in fact, did grow up learning an account of our intellectual history as the story of the steady triumph of science over superstition and ignorance (cf Placher 1989:14). Almost all of these stereotyped contrasts between science and religion, however, assume far too simple a picture of what both science and religion are about. When, therefore, we dig deeper into this complex issue much more is revealed about the philosophical and epistemological complexities of trying to contrast religion and science in this way. What emerges - often surprisingly - is a shared epistemological pattern: a foundationalist notion of empiricist science is, after all, philosophically not all that different from an equally foundationalist conception of biblical literalism of religious fideism. Though scientific materialism 
seems often to be at the opposite end of the spectrum from biblical literalism or theologies that claim self-authenticating notions of divine revelation, their foundationalist approaches may share several characteristics:

* both believe that there are serious conflicts between contemporary science and religious beliefs;

* both seek knowledge with a secure and incontrovertable foundation, and find this in either logic and sense data (science), or in an infallible scripture or selfauthenticating revelation (theology);

* both claim that science and theology make rival claims about the same domain and that one has to choose between them.

Ian Barbour (1990:1ff) has convincingly shown that both these approaches not only prolong a stereotyped conflict-model, but they also represent a misuse of what science and religion are about. The fact that religion and science may in actuality share foundationalist views while at the same time claiming to be in conflict, also reveals why genuine conflicts between religion and science are exceedingly difficult to detect and specify accurately: in retrospect many of the serious clashes between religion and science turn out to be not so much clashes between religion and science, but as clashes between incompatable, even incommensurable world views or philosophies (cf Lash 1985:277). I hope to show in this paper that the current dialogue between religion and science at the very least implies a fall from epistemological innocence as far as this complex and fascinating issue goes.

This epistemological challenge becomes even more fascinating when we take note of remarkable shifts in the minds of scientists who seem to come up against the limits of scientific rationality in their own work. In his important God and the New Physics (1983), Paul Davies still worked from a fairly simplistic but strong contrast between science and religion. The implied conflict between these two explains his reductionist use of scientific explanations to assess religious claims, his startling claim that science offers a surer path to God than religion (cf 1983:ix), and his choice for a 'natural God' who would be wholly within the universe, constrained by physical laws and accessible - at least in principle - to scientific investigation (cf 1983:209). Because of the theory of relativity and quantum theory the 'new physics' not only demands a radical reformulation of the most important aspects of reality, but is as such uniquely placed to provide answers to even ultimate questions formerly reserved for religion only. 
In one of his latest works, The Mind of God (1992), Davies, however, seems to make some important shifts: where previously he came up against a 'natural God' by pushing the logic of scientific rationality as far back as it would go in search of ultimate answers, Davies now acknowledges the 'mystery' at the end of the universe (cf 1992: 223ff). He eventually seems to be arguing for alternative modes of knowledge - even mystical knowledge - as valid ways of understanding the universe, its existence and properties in categories that may lie outside the categories of regular scientific thought.

In a similar vein Bernard D'Espagnat (1989:205) states that scientific rationality has its own inherent limitations, and then argues for a 'window' within scientific rationality that seems to point to a 'more' beyond this kind of rationality: if someone would want to move beyond the limitations of empirical observation and experimentation (the domain of the natural sciences) in a focused concern for the whole of reality, such a project could therefore not in advance be judged to be incoherent, illigitimate or irrational. This window, even if epistemically very small, is an opening made by rational means on the basis of the experienced limitations of scientific rationality, and as such suggests a richer notion of rationality that transcends the purely cognitive dimension of our human knowing. Along the same lines much of modern physics is understood to have done away with the essentially classical ideal of an objective world existing securely out there, waiting to be measured and analyzed by us. Instead, quantum mechanics and relativity challenge the possibilities and limits of empirical knowledge and expose us as inalienable - but also limiting - participants in the world we are trying to understand (cf Lindley 1993:54).

Nuanced views of the limits of scientific rationality such as these become a special challenge to theologians and also scientists who want to move away from the false certainties provided by overblown foundationalist epistemologies. Moving away from the narrow focus on a strictly scientific rationality to broader and alternative ways of understanding may, however, turn out not to be enough and scrious issues remain that need to be addressed.

Special attention needs to be given, for instance, not only to differences and apparent contrasts between science and religion, but also to the important distinction between religion and theology. For instance, it will not be enough to allow only for crucial differences between, say, mysticism and scientific rationality when theological reflection also presents itself as a form of knowledge - and then as a form of rational reflection that not only may differ from mysticism in important ways, but which may in fact even overlap significantly with scientific rationality. Theology, in this reflective mode, may turn out to share more with scientific reflection than with mystical experience. Paul Davies may want to take human reasoning as far as it will go and even- 
tually not opt for mysticism and revelation, even if these - in transcending human reason - may indeed turn out to be valid alternative routes to a more comprehensive form of human knowledge (cf Davies 1992:24ff). In a nuanced notion of theological rationality we may, however, for good reasons choose to see theology (as a reflection on religion and religious experience) not as bypassing human reason at all, and therefore not as an alternative to scientific rationality. It may still transcend and be different from a strictly scientific rationality, but it may at the same time in very important ways turn out to overlap with scientific rationality, and as such share in the human quest for intelligibility and ultimate meaning: a quest that has always been crucial for defining scientific rationality.

At the heart of the contemporary 'religion and science' problem, therefore, lies the deeper problem of how the epistemic values that shape the rationality of religion and of theological reflection, will be different from, or similar to those that shape the rationality of science. The challenge of postmodernist pluralism, of course, makes it virtually impossible even to speak so generally about 'rationality', 'science', 'religion' or 'God'. And yet, even if we should ackrowledge the possibility of radically different forms of rationality, the crucial question still remains whether the rationality of science is in any significant way superior to other forms of rationality.

Mainly as a result of the pervasive influence of the classical model of rationality in our culture, the natural sciences - especially the physical sciences - are indeed still regarded by many as the paradigm for rationality today. Postmodern philosophy of science has recently, however, severely challenged this special status of the natural sciences (cf Rouse 1991). Postmodern philosophy of science understandably rejects epistemological foundationalism as well as all metanarratives that would claim to legitimate scientific knowledge, practices and results. In its extremist form this leads to the dismissal of philosophy of science itself, as our traditional means of gaining an understanding of science (cf Lotter 1994:153ff). On this view traditional philosophy of science is replaced by a postmodern reconstruction of the local activity of scientists, where scientific claims, explanations, procedures and experiments are seen as part of a series of activities situated within the narrative field of science. On this view, then, all global legitimation of the epistemic status and ontological standing of science through philosophical argument is seen as typically modern, and challenged as such.

Postmodernism, however, has proved to be as protean and multi-interpretable as it is challenging. Not only in philosophy of science, but also in the theology and science dialogue, alternative interpretations of postmodern themes, as well as constructive appropriations of some of these, have become viable options. In his seminal work on the nature of rationality, Harold Brown (1990:79ff) too rejects all epistemological foundationalism and argues persuasively that an adequate model of rationality should indeed 
be exemplified by those disciplines that we, with good reasons, take to be paradigm cases of rational endeavor. This ultimately brings us face to face with the important question: Is there a special sense in which science, in spite of the pervasive influence of the positivist or classical model of rationality and the challenge of post modernism in contemporary philosophy of science, still provides us with a crucial test case in our quest for the nature of rationality since it currently still seems to stand as our clearest example of a rational enterprise?.

Today, in a postpositivist and post-Kuhnian age, we know about the interpreted character of all knowledge, about the rediscovery of the hermeneutical dimension of scientific knowledge, and that the rules according to which scientific decisions are made, change as science itself develops (cf Bernstein 1983:30ff; Dean 1988:88). The fact that the rules change shows that they do not meet the conditions of universality and necessity imposed by the classical model of rationality. The historicist turn in philosophy of science initiated by Thomas S Kuhn has thoroughly replaced the foundationalism of the classical model and has opened the way to various attempts at non- or antifoundationalist models of rationality in philosophy of science. In his most recent work Rationality and Science (1993), Roger Trigg alerts us to the dangers of complete relativism that may follow the necessary move away from objectivist notions of truth and verification. In a strong reaction against a modernist notion of rationality that stresses universality and necessity, nonfoundationalism can indeed easily align itself with a relativist mode of postmodern thinking, and as such highlight the fact that every group and every context has its own rationality.

If this nonfoundationalist view were true, then any social or human activity could in principle function as a test case for rationality. This notion would leave us with an extreme relativism of rationalities: a relativism that not only forms the opposite of the classical model's objectivism, but a relativism that would also be devastating for any intersubjective truth claims in both scientific and theological reflection. Proponents of the relativism of this 'many rationalities'-view hold that the rules which govern science are internal to science in the same way that other human activities (cf religion, business, magic etc) are also governed by rules internal to them. In the relativism that flows from this nonfoundationalisn it is therefore maintained that each area of human activity has criteria internal to a specific culture or social group. Since each area can therefore claim its own criteria of rationality, there can be no independent framework for deciding whether one framework is more rational than another (cf Brown 1990: 113). According to this view science, along with religion, is seen as just one more feature of postmodern Western society, where all cultures or societies create cognitive structures that explain the world around them. This view also obviously denies that the body of beliefs developed by science could be in any way cognitively superior to other beliefs. 
Over against the objectivism of foundationalism and the extreme relativism of most forms of nonfoundationalism, some of us want to develop a postfoundationalist model of rationality that is thoroughly contextual, but which at the same time will attempt to reach beyond the limits of its own group or culture in interdisciplinary discussion. This view of rationality aims to capture those features of science which indeed make it a paradigmatically rational enterprise without falling back onto the foundationalism of the classical view of rationality. It is only within a postfoundationalist view of rationality very similar to this that Harold Brown can persuasively argue that, while science did indeed develop in the Western world, there are still powerful grounds for maintaining that science has a significance that indeed transcends the particular culture in which it first appeared (cf Brown 1990:114).

Whatever else a postfoundationalist model of rationality might mean, it certainly means at least the following: while we always operate in terms of concepts and criteria that appear within in a particular culture, we are nonetheless able to transcend our specific contexts and reach out to more intersubjective levels of discussion. Over against a nonfoundationlist 'many rationalities' view then, a postfoundationalist model of rationality wants to show that science can indeed be a potential and reliable source of knowledge that not only transcends the cultures in which the various sciences first appeared, but can also epistemically relate to broader and different notions of rationality.

This relates closely to the fact that post-Kuhnian philosophy of science has shown us that there can be no sharp line of demarcation between scientific rationality and other forms of rationality (cf van Huyssteen 1989:63ff). In fact, scientific rationality relates to a pre-analytic reasonableness of a more basic kind of human rationality that informs all goal-directed action. Within this broader context Christian theology too should seek as secure a knowledge as it can possibly achieve, a form of knowledge that will allow an optimal understanding of that to which Christian believers are committing themselves in faith. In the end this epistemic goal of theological reflection, more than anything - and in spite of important differences between a theological and a strictly scientific rationality - will determine the shaping of the rationality of theological reflection. And if in both theology and science we strive to explain better in order to understand better, then surely the epistemological problem of the nature of rationality should be one of the most important foci of our attempts to meaningfully relate religion and science to one another today.

The complexity of the nature of human rationality and the way this plays out differently in religion and science, thus reveals that there are no easy ways to bridge the gap between these two in terms of 'conflict', 'dialogue', or even 'consonance'. This is 
eminently revealed when for a moment we briefly look at the history of the relationship between scientific cosmology and the Christian doctrine of creation. At the beginning of the early Medieval period Jews, Christians and Muslims were in agreement about at least one theological 'given': the universe had a beginning in time. This, of course, was based on the Genesis story of the creation, and Augustine, who in principle was willing to take the road of metaphor to avoid any conflict with 'demonstrated truths', was keen to show that there was no conflict here: creation was seen as a single timeless act through which time itself came to be (McMullin 1981:28).

The rediscovery of Aristotle, first in Islam and then in the Latin West, introduced a new challenge to the Christian doctrine of creation: Aristotle argued strongly that neither matter nor time could have a beginning. Aquinas would later show that neither side of this debate could be demonstrated philosophically. Much later the numerous traces of historical development on the earth's surface, and the discovery of the second law of thermodynamics, made the Aristotelian notion of an unchanging, eternal cosmos seem quite implausible (cf McMullin 1981:30). Even later Einstein's general theory of relativity, combined with Hubble's discovery of the galactic red shift, would lead to the widely acclaimed postulate of an expanding universe, or the so-called Big Bang theory, according to which a singularity is postulated about 15 billion years ago from which the expansion of our universe began. The importance of the Big Bang theory is easily recognized: for the first time physics was led by its own resources to something that sounded like a beginning of time (cf Drees 1990:17ff; 211ff). This was followed by responses that ranged from positions like that of Pope Pius XII who hailed the theory as unqualified support for the Christian idea of creation, to rejection because it looked too much like creation, or conflicted with fundamentalist notions of a creation only a few thousand years ago.

It is clear, however, that none of these positions take the complexities of the relationship between scientific and theological rationality into consideration at all. Not only can the Big Bang not automatically be assumed to be either the beginning of time or of the universe, but it also cannot be taken for granted that the lapse of time since the so-called Big Bang is necessarily the age of the universe (cf McMullin 1981:35). The Big Bang theory and scientific cosmology in general - as Willem Drees (1990) has recently pointed out - is not in the first place about the universe, but rather about its subsequent evolution.

Stephen Hawking's question 'did the universe have a beginning in time, and what is the nature of time'? (cf Hawking 1988:1), therefore has to be very carefully defined both scientifically and theologically. But in the same careful way we have to realize that the deepest religious intent of, for instance, the Genesis passages in Christianity's classic text, is to underline the dependence of an intelligible and contingent universe on a Creator, and not necessarily to specify a first moment in time. 
This example from the history of Western thought alerts us to the epistemological fallacy of directly inferring from contemporary science to theological doctrine. It would be a serious category mistake to infer directly from, for example, the Big Bang to creation, from field theory to the Spirit of God, from chance to divine providence, from entropy to evil, or from the anthropic principle to design. The Big Bang theory, for instance, does not entitle us to infer - theologically or otherwise - an absolute beginning in time. On the other hand, there is nothing scientifically or philosophically inadmissable about the idea that an absolute beginning might have occured. And if it did occur, it could look something like the horizon event described by the Big Bang theory. But to eventually describe this horizon event in Christian terms as 'the Creation' would be to explain it in terms of a cause that would not be scientific anymore.

All of this now leads up to the important question: what could a theologian then rightly infer from this highly successful theory? It would be possible to say, theologically, that if our universe had a beginning in time through the unique act of a creator, from our point of view it would look something like the Big Bang cosmologists are talking about. What one cannot say, is that the doctrine of creation 'supports' the Big Bang model, or that the Big Bang theory 'supports' the Christian doctrine of creation (cf McMullin 1981:39). As Christians we should therefore take very serious the theories of physics and biology: not to exploit or to try and change them, but to try to find interpretations that would suggest a hypothetical consonance with the Christian viewpoint. Theology can, therefore, never claim to be capable of scientific theoryappraisal, but should rather be seen as one important element in the construction of a broader cultural world-view (cf McMullin 1981:51). The Christian can never seperate her or his science from her or his theology, but she or he should also learn to distrust epistemological short cuts from the one to the other. One way to do this would be to find a conceptual framework that would yield a fine-tuned epistemological consonance by carefully focussing on the nature of rationality in theology and science.

As a first step towards a broader and richer notion of rationality, we can now follow the lead of Nicholas Rescher $(1989,1992)$ and identify at least three sources of rationality that are highly relevant not only for the natural, the social and the human sciences, but also for theology as a reflection on religious experience: the cognitive context, the evaluative context, and the pragmatic context. None of these resources of rationality has priority over any of the others, even if cognitive rationality, or the cognitive dimension of rationalty, is often dominant in intellectual issues. In both science and theology we are therefore challenged to sound, rational judgment in our quest for intelligibility: good reasons for hanging on to certain beliefs, good reasons for making certain moral choices, and good reasons for acting in certain ways. Within a holist epistemology these three go together as a seamless whole and merge in the common task of uniting the best reasons for belief, evaluation and action. 
In his move to an alternative, post-classical model of rationality, Harold Brown (1990:137; cf van Niekerk 1990:180) links on to the evaluative resources of rationality by highlighting the role of judgment in human cognition. Judgment in this broader epistemic sense is the ability to evaluate a situation, to assess evidence and then come to a reasonable decision without following rules. In Brown's concept of rationality judgment plays a crucial epistemic role, and its focus on the particular and the contingent - instead of the general and the necessary - is a very definite step beyond the classical model of rationality's foundationalism. Brown argues persuasively that we cannot understand human knowledge fully without recognizing the role that judgment plays at key epistemic junctures. Judgments must be made by individuals who are in command of an appropriate body of information that is relevant to the judgment in question. Brown (1990:137) therefore develops the idea of rational judgment and intersubjective criticism as epistemic skills that should be performed by experts. Brown's notion of the role of judgment in rational decision-making is exciting because in the end it frees us from the idea that only infallibility or perfectability counts in epistemic matters. When at any point in time we make a decision for something in the light if the best reasons available to us, there need be no incompatability between accepting a set of fallibile claims for a substantial period of time, and being prepared to reconsider them when we have good reasons for doing so. On this view the development of cognitive skills is closely analogous to the development of physical skills, and the conscious, explicit, rule-following that has long been taken as the paradigm of intelligent mental life indeed captures only a small portion of our cognitive resources (cf Brown 1990:177).

Earlier we saw that perhaps the most central idea in our preanalytic concept of rationality is that we normally have good reasons for our rational beliefs. And precisely because our rational beliefs are based on good reasons, we also regard them as more rational than nonrational or. irrational beliefs. Next to rational beliefs, however, we also need to identify rational persons, that is persons who can exercise good sense and good judgment in difficult and complex circumstances. We expect a rational person to be open to new ideas, and — as Harold Brown (1990:183) puts it to function well in the context of discovery. Brown therefore wants to retrieve neglected features of the classical concept as a possible basis for an alternative model of rationality. He does this in three steps:

* In the first place the notion of a rational agent is taken as fundamental, and notions like 'rational belief' are seen as derivative in the sense that a rational belief will be one that is arrived at by a rational agent (Brown 1990:185). Moreover, the classi- 
cal notion of rationality stresses the idea that a belief's rationality is connected with the way we arrive at that belief, that is by way of a body of appropriate evidence, which then makes it a rational belief. This aspect of the classical model of rationality is now included by Brown in his own model, but it is developed very differently. In the classical model the central emphasis is placed on the logical relations between the evidence and the belief, while the role of the agent is minimized. In the new, alternative model the agent is taken to be basic, and the way that an agent deals with evidence in arriving at a belief, will be determinative of the rationality of that belief for him or her (Brown 1990:185).

* The ability to make judgments in those situations in which we lack sufficient rules to determine our decisions, is seen as a characteristic feature of a rational agent. Like in Rescher's model, the evaluative dimension and the accompanying notion of judgment here becomes central to this model of rationality. It futhermore also entails that our ability to act as rational agents is limited by our expertise (cf Brown 1990:185). This does not mean that only experts can be rational, but it does mean that in cases where I may lack expertise, there may be only one rational decision open to me: to seek expert advice.

* The third step required for Brown's alternative model is the introduction of a social element (cf Brown 1990:187): rational decision-making is a socially mediated rather than a rule governed process (cf van Niekerk 1990:184). For a belief based on judgment to be a rational one, it must be submitted to the community of those who share the relevant expertise. This demand that rational beliefs be subject to evaluation and criticism, is in conformity with our normal understanding of rationality.

Brown now correctly argues that this idea can be developed without its foundationalist implications, precisely by taking rationality to be a social phenomenon. Judgment therefore becomes necessary exactly when no general rules are available, and rationality thus always requires other people. And not just any people, but people with the skills needed to exercise judgment on a particular issue within a specific context.

Brown here differs significantly from Thomas Kuhn and his consensus model of rationality. For Kuhn the social aspect replaces positivist rules as the basis for scientific research and decision-making, rational decisions are those made by the scientific community, and in normal science these become embodied in communally approved and transmitted practices (Brown 1990:191). Kuhn thus holds to the position that when the majority of a relevant scientific community reaches agreement, we have a 
rational decision. Brown, however, differs from Kuhn precisely at this point: agreement with the majority does not automatically make a belief rational. Brown's model requires only that individuals submit their judgments for evaluation by their peers, and that they take this evaluation seriously. This is also much closer to real-life situations where, as academics and even as Christian theologians, we often hardly agree at all. Brown's model thus does not require that each member of the community agrees with the majority, since agreement with the majority view is neither necessary nor sufficient for rationality (cf Brown 1990:192). Scientific practice clearly demonstrates that rational disagreement is a pervasive feature of science. Brown's model therefore allows for, and accepts that human judgment is always fallible, and that our bests chance of eliminating error is by exposing our judgments and decisions to the critical scrutiny of other people.

In a postfoundationalist notion of rationality, therefore, the predicate 'rational' characterizes an individual's decisions. It does not - in the first place at least - characterize beliefs, propositions or communities. Even if a community of experts is necessary for an individual to arrive at a rational belief, it still is the individual's belief that is rational, and not the community (cf Brown 1990:193). Brown's alternative model of rationality makes the human agent who exercises judgment central to rational procedures, and it is the fallibility of this judgment that leads to the requirement of critical evaluation. And because of the way judgment is exercised here, our interpreted and traditioned experience enters the process that leads to rational judgment, even if we cannot always capture the experience in propositions.

At this point, however, we are faced with an important question: how does Brown's alternative model of rationality get him beyond the social relativism of nonfoundationalism? If rationality involves nothing more than judgment and critical evaluation by the members of an appropriate community, then we may find rational belief and decision-making in communities that may even be characterized as irrational. For Brown (1990:194) theologians are a case in point: 'Various groups of theologians who belong to different religions may all be engaged in a fully rational endeavor, and the same may hold for, say, Azande witch doctors'. Brown is fully aware of the fact that this possibility follows from his model of rationality, and therefore argues along the following lines:

* to claim that a belief is rational is not the same as to claim that a belief is true;

* while rational acceptance of a claim indeed depends on the assessing of evidence, some forms of evidence provide a stronger warrant for belief than other forms of evidence. In his own words: 'Thus while questions of denominational theology 
may be capable of a rational solution, it does not follow that we have no basis at all for choosing between, say, a scientific and a theological world-view at those points at which the two views conflict' (Brown 1990:195).

Although on this view theological rationality still seems to come a distant second to scientific rationality, Brown's argument for a richer notion of rationality does show that rationality in the classical sense is not at all enough when it comes to the cognitive assessment of knowiedge claims. A postfoundationalist notion of rationality therefore does not return us to the relativist position according to which every group or language game is automatically rational in terms of its own internal rules. This model indeed involves tighter constraints, and therefore moves beyond just agreed upon rules to submitting results for critical evaluation by experts in the field. On this view not rationality, but rational beliefs are always situated contextually. The thesis that, what is rational to believe or do is relative to a particular situation, should therefore not be confused with the thesis that rationality itself is relative.

The relation between rationality and context invariably raises the question of the relation between rationality and truth. It does seem that the notion of truth is so deeply embedded in our thinking about cognitive matters that we can barely get along without it (Brown 1990:198). On the classical notion of rationality there is a close tie between rationality and truth, and for this reason false propositions could never be rationally accepted. Contemporary antifoundationalist and postmodern thought, on the other hand, emphasizes that people from different societies can accept radically different sets of claims as true, and that it is impossible to determine which of these claims are really true. Both Kuhn (1970) and Laudan (1977) have also shown that human beings have managed to function very successfully on the basis of beliefs that they later reject as false.

It is, however, extremely difficult to dispel with the notion of truth completely (cf Brown 1990:197). Whatever we say or claim about truth or true premises does us little good unlèss we have reasons for believing that they are indeed true. This, according to Brown (1990:201), is where rationality enters the picture, since rationality is concerned with assessing reasons for believing one claim or another. This of course makes the great attraction of the classical model and the search for foundations so understandable. The epistemic failure of foundationalism, however, has left us without any strong truth claims: the only reasons we now have for hanging on to our cognitive claims are that we judge them as the best ones available to us.

Brown's (1990:202) point is that the notions of truth and rationality are distinct in the sense that achieving one of them in no way entails that the other has also been achieved. 
There is, however, a weaker but vital tie between rationality and truth: we proceed rationally in attempting to 'discover' truth, and we take those conclusions that are rationally acceptable in terms of our own judgments, as our best estimates of the truth. Brown thus argues persuasively that the search for truth is a long-term process and that we need coherent procedures to carry out this pursuit for optimal intelligibility, which for Brown is the ultimate function of rationality (cf Brown 1990:202). Brown's argument for a weak tie between truth and rationality indeed turns out to be very persuasive for any attempt to arrive at a plausible postfoundationalist notion of progress in science. Even if we are committed to the view that later theories are better theories, it does not have to imply a closer-to-the-truth position. In his argument against such a theory of verisimilitude, Nicholas Rescher too warns against the temptation to think of improvement in warrant (having better reasons) in terms of improvement in approximation (moving closer to the truth; cf Rescher 1992:48). In fact, since we now accept that science often progresses through revolutions and radical shifts, there is no way that we can still think of science as developing by way of convergence or accumulation.

What is achieved in scientific inquiry is therefore not an approximation of truth but an estimation of it: scientists form, as best as they can, a reasoned judgment of where the truth of the matter lies. In this way we too do not manage to get nearer to 'the truth', but we do present our best estimates of what we believe the truth within a specific context might be. On the level of scientific theorizing, our present world picture thus represents a better estimate than our past attempts only in the sense that it has accomodated, comparatively speaking, a wider range of data. This fallibilism is also strenghtened by Rescher's consistent and helpful distinction between a better estimate (one that has fewer deficits and may be based on fuller information) and a closer estimate (one that claims to be closer to the 'real truth'): in scientific theorizing we must settle for a qualitative 'better' because there is obviously just no way of monitoring the issue of a measurable 'closer' (cf Rescher 1992:53). The fact that scientific knowledge also moves through radical changes and discontinuities thus invalidates any talk of successive approximation.

Our accepted truths - in both science and theology - should therefore be viewed as nothing more than the best estimates that we are able to' make in the present moment. For pragmatic reasons, however, it might still make sense to talk about 'pursuing truth' (cf Rescher 1992:56).

A postfoundationalist model of rationality thus preserves the idea of progress, and also that rational beliefs are based on good evidence, although there now are different sources of evidence for different claims. This becomes even clearer when we take a closer look at the concept of objectivity. Obviously we first need to disassociate our- 
selves from the view that objectivity requires that we approach our subject without any preconceptions. What Brown argues for is that objectivity means at least this: that the evidence or good arguments supporting an objective belief must derive from a source that is independent of that belief (Brown 1990:203). The example that Brown uses to illustrate this is taken from physics: a physicist, working within a certain historical and social context, might claim that all matter is constructed of electrons, neutrons and protons. What is normally claimed here is that these are actually features of the physical world. Of course these claims, like all intellectual or specifically scientific claims, are made from a certain historical and social context. Brown correctly argues, however, that such claims are nevertheless not solely claims about that context, culture or language. One of the things that language permits us to do is precisely to make claims about items that exist apart from us and our language (cf Brown 1990:203).

So, once we have acknowledged the cultural, linguistic or social context of a claim, the point remains that many claims make assertions about some state of affairs that is independent of those claims. For Brown (1990:204) these are paradigm examples of the pursuit of objectivity, and as such come very close to what Nicholas Rescher has called the pursuit of truth. It is, of course, important to remember that not all matters can be studied objectively: some subjects may not have what Brown (1990:205) has called a 'required ontological status'. We have, for example, no objective basis for evaluating ethical claims. This, however, does not by itself block the exercise of rationality in these fields, for there may be other considerations that can provide the basis for rational evaluation. One may, for example, have good reasons for believing that an ethical system ought to have a certain degree of coherence (cf also theology), and that this should provide grounds for rationai analysis.

This argument for a weak notion of objectivity is certainly not meant to function as a basis or 'foundation' for a strong metaphysical realism. What is argued for, is that we normally study items or issues that are relatively independent of the claims we make about them. Even more crucial, however, is to always carefully distinguish between rationality and objectivity: rationality (cf in theology) is indeed possible even in the absence of regular scientific objectivity. Still, objectivity remains epistemically important because it provides us with an especially powerful body of evidence to be used in the rational assessment of our claims.

This discussion of the role and characteristics of truth, progress and objectivity in science brings us to the problem of the status of science, and to how much we can hope to achieve through scientific knowledge vis a vis theological knowledge. The key question here is: how far can the scientific enterprise advance toward achieving complete intelligibility or a definite understanding of nature? The fallibilism implied in a post- 
foundationalist notion of scientific rationality necessarily leads to what has been called the imperfectability of science (cf Rescher 1992:77f). A fallibilist epistemology necessarily implies that our knowledge - even our scientific knowledge - can never be complete or perfect. For Nicholas Rescher (1992:85) this fait accompli invites a description of the cognitive situation of the natural sciences in theological terms: expelled from the Garden of Eden, we are deprived of access to the God's eye point of view. We yearn for absolutes but have to settle for plausibilities; we desire what is definitely correct, but have to settle for conjectures and estimates. The ideal of a perfected science, though unattainable, is nevertheless epistemically highly useful. Rescher calls this idea of a perfected science a focus imaginarius whose pursuit canalizes and thereby structures our scientific inquiry: 'As such it represents the ultimate telos of inquiry, the idealized destination of an incompletable journey, a grail of sorts that we can pursue but not possess' (Rescher 1992:94).

With this we have again returned to one of our most important initial questions: if scientific knowledge itself is so imperfect and essentially fallibilist, why does it provide such an important test case for our reflection on rationality, and for our attempts to discern a meaningful epistemological consonance between science and theology? Having moved beyond the foundationalism of the classical model of rationality and its restrictive notions of verification and empirical evidence, it now becomes possible to claim the following: rationality, specifically a postfoundationalist notion of rationality, still requires serious assessment of evidence, and we should therefore find our best examples of rationality in an area or field where the most reliable evidence is systematically gathered and deployed. Objective procedures still provide the richest and most reliable evidence, and one of the most important features of science is precisely its systematic pursuit of objective evidence (cf Brown 1990:207).

With this, I think, the selection of science, as possibly our best example of the cognitive dimension of rationality at work, is indeed still justified. This special position of science, which now, in a much more qualified sense, is still the paradigm of rationality at work, is ultimately. also the reason why contemporary philosophy of science still forms the most important epistemological link in the current religion and science debate. What is not justified, however, is any claim that uncritically extends the nature of a strictly scientific rationality to the rationality of religious or theological reflection. Because of the nature and the comprehensive resources of human rationality, the rationality of science and the rationality of religious reflection do seem to overlap at some very crucial junctures. The theologian shares with the scientist the crucial role of being a rational agent, of making the best possible rational judgments within a specific context and for a specific community. The theologian also shares with the scientist the fal- 
libilism implied by the contextuality of rational decision-making, and thus the experiential and interpretative dimension of all our knowledge. Precisely the experiential and interpretative roots of religious knowing, however, are much more complex than the mostly empirical roots of scientific knowledge. Rationality in religion and in theological reflection is therefore indeed a broader and more complex affair than what emerges as a strictly scientific rationality (cf Moore 1994). The lingering imperialism of scientific rationality should, however, not close our eyes to the remarkable epistemic consonance between scientific and theological ways of thinking. At the same time some scientists and philosophers of science, as we saw before, are acknowledging the limitations of scientific rationality too (cf D'Espagnat 1989; Davies 1992), and are thereby also opening the way to the acknowledgement of broader notions of rationality.

The close ties between science and rationality of course present the religion and science debate with yet another challenging question: why is natural science possible at all? What happens so that the lawful order of nature becomes intelligible to us in the conceptual terms that we have devised? Philosophers such as Nicholas Rescher, and scientists such as Paul Davies have persuasively argued that the problem of the intelligibility of nature is eminently expressed in the question of the cognitive accessibility of nature to mathematicizing intelligence (cf Rescher 1992:99). In fact, the belief that the underlying order of the world can be expressed in mathematical form lies at the very heart of science, and as such is rarely questioned (cf Davies 1992:140). Rescher's answer to this crucial question not only reveals a postfoundationalist move to an interactionist or relational model of rationality that enables him to transcend the rigid realism/anti-realism debate, but also gets him to a position that is very close to what Jerome Stone (1992) has called transactional realism: the answer to the question of the cognitive accessibility of nature to mathematizing intelligence can only be found in a somewhat complex, two-sided story in which both sides, intelligence and nature, must be expected to have a part (Rescher 1992:99). This of course is consonant with the most basic thrust of a modest form of critical realism: it is precisely the interaction between our thoughts and the world which conditions our sense of order, beauty, regularity, symmetry and elegance. Evolutionary pressure thus coordinates the mind with its environment. For Nicholas Rescher this leads to a crucial epistemological insight: the mathematical mechanisms we employ for understanding our world reflects the structure of our (interpreted) experience. In this sense it is no more a miracle that the human mind can understand the world through its intellectual resources than that the human eye can see it through its physiological resources (Rescher 1992:100).

A model of rationality that in this interactionist way allows us to acknowledge that we devise our mathematics and science to fit nature through the mediation of experience, reveals an unexpected epistemological consonance between theology and science: I have argued before that all religious (and certainly all theological) language 
reflects the structure of our interpreted experience (cf van Huyssteen 1993:253-265). In science our concepts and theories can therefore be seen as products of an interaction in which both nature and ourselves play a formative role. To talk abstractly about the intelligibility of nature, about the regularities of nature and the laws that express them, indeed remains incomplete until we answer the more basic question: intelligible for whom? This frees us to realize that science, like all intellectual endeavors is, in Rescher's words, our science. This implies that reality can never be described or presupposed in any absolute way, but is known through investigator-relative results that will differ with different modes of interactions between our world and us (cf Rescher 1992:111).

What is at stake in this postfoundationalist model of rationality, is therefore not so much the ontological question as to the existence or not of the 'real world' (mindindependent or not, as in the realism/anti-realism debate), but rather the status of our knowledge of reality as presupposed in the epistemic process. Rescher (1992:119) also convincingly argues, in his own way, that regardless of the extent to which reality may be 'mind-independent', our knowledge of this reality represents information grounded only in an interpretation of our experience. What is relevant and important for us therefore depends on how we go about experiencing our world, and how we interact with what we see as reality.

For the religion and science discussion a plausible epistemological consonance emerges only on this level: as we have seen, the resources of rationality are indeed broader than just cognitivity. But epistemological fallibilism and rational accountability become viable options only when we realize that our exclusive cognitive access to reality is via the construction of a 'world picture' or models in which our own intellectual resources play a crucially conditioning and shaping role.

Obviously the issue of objectivity (in the sense of mind-independence) is pivotal for any form of realism. Rescher (1992:256) argues that realism in this broad sense has two inseperable and indispensable constituents - the one existential and ontologi$\mathrm{cal}$, the other cognitive and epistemic. The former maintains that there is indeed a real world, a realm of mind-independent, physical reality. The latter maintains that we can to some extent secure information about this mind-independent realm. What is crucial about Rescher's position on realism - vis a vis strong forms of scienctific realism (that argue for realism on the basis of the success of science), and also some forms of critical realism that attempt to ground reference to reality in a correspondence view of truth is that the ontological component of this philosophical realism is not a matter of discovery or the result of argument, but rather a functional or pragmatic presupposition for our inquiries (cf Rescher 1992:257). Without this presupposed conception of reality it 
would be hard to maintain a fallibilist epistemology. The justification of this fundamental presupposition of objectivity is not evidential, and therefore not foundationalist: it is, rather, a functional one.

This account of the pragmatic basis of a weak form of realism thus results in a truly postfoundationalist move: on this view realism is a position to which we are constrained not by the push of evidence, but by the pull of purpose (cf Rescher 1992:270). Realism in this mode does not represent a discovered fact or a justified position, but rather the methodological presupposition of our praxis of inquiry. Traditional realists see the basis for realism in the success and progress of science (cf Leplin 1984:1-8). Because of its necessary fallibilism, however, a pragmatic form of critical realism implies an epistemic humility that pivots on the inevitable provisional character of all our knowledge and on the the idea that - whether in theology or science - there is more to reality than we can actually know. A postfoundationalist notion of rationality, shared as a rich and mutual source by both science and religion, thus reveals an epistemic consonance that transcends the important differences between scientific and religious reflection. In so doing it honors the provisional, contextual and fallibilist nature of all human knowledge while at the same time enabling us to retain our ideals of truth, objectivity, rationality and progress.

Thus, once again, a broader and richer notion of human rationality is revealed with its distinct cognitive, evaluative and pragmatic dimensions. Whether in religion or science, in each of these fields we have good reasons for hanging on to certain beliefs, good reasons for making certain judgments and moral choices, and good reasons for acting in certain ways. In theology, as a critical reflection on religion and religious experience, rationality implies the ability to give an account, to provide a rationale for the way one thinks, chooses, acts and believes. Here too theory-acceptance has a distinct cognitive dimension. When we ask, however, what besides belief is involved in theory-acceptance, the pragmatic and evaluative dimensions of theory-acceptance are revealed (cf Van Fraassen 1989:3ff). Here the rationality of science and of theology very much overlap in that both exibit what intellectual practice would be like for those who adopt a specific model of thought. From this it does not follow that the natural sciences are 'just like' theology at all. Furthermore, what sets science apart is not at all that decisions between scientific theories are made by some objective procedure, a procedure forever unavailable to theological decision-making (cf Placher 1989:50).

In both theology and science, then, rationality pivots in the deployment of good reasons: an act of judgment in which we, through believing, doing, choosing the right thing for the right reasons, become rational persons. Being rational is therefore not just a matter of having some reasons for what one believes in and argues for, but having the 
strongest and best available reasons to support the rationality of one's beliefs within a concrete context. The hazy intersection between the diverse fields of theology and the other sciences is therefore not in the first place to be determined by exploring possible methodological parallels or degrees of consonance between theology and science. What should be explored first is a common and shared resource found in a richer notion of human rationality, even if these important epistemological overlaps sometimes are overwhelmed by equally important differences beween religion and science. Thus too are revealed the unacceptable epistemological short cuts that come into play when the rationality of science is contrasted with the so-called irrationality or non-rationality of religion, or even when the rationality of religion, and of theological reflection, is proclaimed to be radically different in every possible respect from scientific rationality. We row know that rationality can not be narrowed down to a strictly scientific rationality, and scientific rationality cannot be reduced to natural scientific rationality.

I would therefore like to claim that the quest for intelligibility and ultimate meaning in theology is also dependent on broader resources than just the purely cognitive, that is on the evolving nature of the epistemic values that have shaped theological rationality in history.

But what does this imply concretely for theology? At the very least it implies that the realist assumptions and faith commitments of experienced Christian faith are relevant epistemological issues to be dealt with seriously in the theology and science discussion. By doing this, theology could move away from the absolutism of foundationalism as well as from the relativism of nonfoundationalism. This can further be achieved by showing that because theology is an activity of a community of enquirers, there can be no way to prescribe a rationality for that activity without considering its actual practice, along with the way this reflective practice grows out of the way Christian believers live a daily life of faith.

The 'science and religion' discussion in a very specific way therefore reveals how the explanatory role of interpreted experience in theology can only be adequately appreciated in terms of an experiential epistemology. This not only means that religious experience is better explained theologically, but that in explaining the role of experience, the philosophical theologian will have to move from the question of rationality to intelligibility, from intelligibility to the question of personal understanding, and from personal understanding to personal experience. This is something the scientist need never do when doing science. Dealing with personal commitment in this way may show that the rationality of religion, and therefore of theology, is often shaped by epistemic values different from that of science. The dependence of theology on this kind of experiential adequacy for determining and maintaining its explanatory adequacy, need, however, never again mean that theology is less rational or less contextual, for that matter, than science. 
The nature of the ongoing discussion between theology and science should help us to realize that, in spite of a promising and emerging new field of study, the complex relationship between scientific and religious epistemology is more challenging than ever. This becomes all the more clear when we keep in mind not only the deconstruction and discovery of the limitations of the natural sciences in the post-Kuhnian era, but also when we focus carefully on the nature of the natural sciences. The sciences are eminently competent when it comes to theory construction and to experimental and pragmatic enterprises, but they are unqualified when it comes to finding answers to our deepest religious questions. In religion, and in theological reflection, we go beyond strictly scientific reflection when we focus on the role of story and ritual, and on the often noncognitive functions of religious models in evoking attitudes and encouraging personal transformation (cf Barbour 1990:66ff).

The fundamental differences between religion and science should therefore be respected, as well as the difference between different forms of explanations in not only the different sciences, but also between theology and the other sciences. However, in spite of important differences and sometimes radically different levels of explanation, theology and science do share common resources of rationality. A theology and a science that come to discover this mutual quest for intelligibility in spite of some very important differences, will also be freed to discover that nothing that is part of, or the result of natural scientific explanation, need ever be logically incompatible with theological reflection. Science can tell us little or nothing about our experience of subjectivity, about the astonishing emergence of human consciousness and personhood, and about why we have an intelligible universe. God is the name that Christian believers give to the best available explanation of all that is (cf Peacocke 1990: 134).???nie in literatuurlys

In focusing on the importance of the natural sciences, we should then have an openness for that which reaches beyond the world of the natural sciences, that is, to the world on which the social sciences, history, philosophy and theology focus. In this wider context we could discover that theology and science both share not only a mutually enriching quest for intelligibility, but also share the importance of tradition and of the explanatory. role of interpreted experience. An honest analysis of the differences between the sciences and between theological and scientific explanations might then yield more intelligibility in the apologetic attempt to understand our postmodern world as truly God's own world.

In conclusion: in this paper I have tried to address three important questions: 
* Are there good reasons for still seeing the natural sciences as our best available example of rationality at work?

* If so, does the rationality of religion and of religious reflection have anything in ' common with scientific rationality, and what would the significance of these epistemological overlaps be?

* Even if there are large and impressive overlaps between these two modes of rationality, how would the rationality of science and the rationality of religious reflection be different?

My conclusion has been that science can still, but in a qualified sense, be seen as the best available example we have of human rationality at work. This does not mean that science or scientific rationality is in any way superior to other modes of rationality. On the contrary, a postfoundationalist notion of rationality reveals rich and complex resources for human rationality that are shared by scientific and religious reflection. With this it also has been possible to reject a nonfoundationlist 'many rationalities' view in which science and religion represent radically different and often incommensurable forms of life.

Today, in our postmodern culture, not only religion, but also science turns out to be a surprisingly pluralist affair (cf Placher 1989:14f). With the demise of positivism and the classical model of rationality, the claim that the problems of pluralism and relativism in science can be solved by appealing to universality and objectivity on the basis of scientific method, is long gone. Different modes of rationality should therefore today not be judged in terms of a superior scientific rationality, but should be judged by the way in which they share in the common cognitive, evaluative and pragmatic resources of human rationality.

It would therefore not be justified to extend the nature of a strictly scientific rationality to the rationality of religion or theological reflection. The theologian, in her or his reflection on the meaning of religious experience does, however, share with the scientist the following:

* the crucial role of being a rational agent, and of having to make the best possible judgments within a specific context, and within and for a specific community;

* the epistemological fallibilism implied by contextual decision-making;

* the experiential and interpretative dimension of all our knowledge; 
* the fact, therefore, that neither science nor theology can ever have demonstrably certain foundations.

The methods of science, as our best example of cognitive rationality at work, are therefore unique: but not unique in the sense of providing a uniquely rational or uniquely objective way of discovering truth. Science is unique only because of its history of success in coping with the problems of empirical reality.

Beyond the fact that religion and science share the rich resources of human rationality, it always remains important to take note of the equally important differences between scientific and theological rationality. William Stoeger (1988:232f) has recently and successfully argued that we should move away from simplistic contrasts between religion and science which often try to pinpoint the difference between the two in terms of their very different objects. The difference between these two claimants to human rationality is not, for instance, based only $n$ the difference between 'empirical problems' and 'religious mysteries'. The difference between the two is a much more refined one, and is found rather in significant differences in focus, experiential grounds and heuristic structures. Stoeger, therefore, is right: in the 'religion and science' discussion, like in any interdisciplinary discussion, what is important is more than differences in object, language and method. What is important, is the often radical differences in epistemological focus and evidential grounds (cf Stoeger 1988:233).

A postfoundationalist notion of rationality should therefore be able to open our epistemological eyes to broader and more complex notions of rationality, where scientific rationality - even if still our best example of rationality at work - cannot and should not be taken as normative for religious faith. And although theology, as the reflection on this religious faith, shares with science the contextual, experiential and interpretative dimension of all human knowledge, the experiential and interpretative roots of religious knowing is always much more complex than the experiential and interpretative roots of empirical, scientific knowledge. Religious beliefs can therefore not be too easily linked to empirical hypotheses because they grow out of much more complex situations.

Religion and religious faith (and theological reflection, in spite of important epistemological overlaps with scientific reflection) are therefore in many ways not like science at all: for the adherents of many religious traditions, faith involves not just a way of looking at the world, but also a personal trust in God. An ultimate faith commitment to God is, in this respect, more like trust in a friend or a spouse than like 
belief in a scientific theory (cf Placher 1989:141). On this very personal level religion and science indeed seem to be very different kinds of activities, each with their own rules in their own domains, but neither one necessarily less rational than the other.

\section{Works consulted}

Barbour, I 1990. Religion in an age of science. San Francisco: Harper and Row. Bernstein, R J 1983. Beyond objectivism and relativism. Oxford: Basil Blackwell. Brown, H 1990. Rationality. London/New York: Routledge.

Davies, P 1983. God and the New Physics. New York: Simon and Schuster.

- 1992. The mind of God: The scientific basis for a rational world. New York: Simon and Schuster.

Dean, W 1988. History making history: The new historicism in American religious thought. New York: SUNY.

D'Espagnat, B 1989. Reality and the physicist. Cambridge: CUP.

Drees, W B 1990. Beyond the Big Bang: Quantum cosmologies and God. La Salle: Open Court.

Hawking, S 1990. A brief history of time. New York: Bantam Books.

Kuhn, T S 1979. The structure of scientific revolutions. Chicago: The University of Chicago Press.

Lash, N 1991. Production and prospect: Reflections on christian hope and original sin, in McMullin, E (ed), Evolution and creation, 273-289. Notre Dame: The University of Notre Dame Press.

Laudan, L 1977. Progress and its problems: Towards a theory of scientific growth. London: Routledge and Kegan Paul.

Lindley, D 1993. The end of physics: The myth of a unified theory. New York: Basic Books.

Leplin, J 1984. Scientific realism. Berkeley: University of California Press.

Lotter, H P P 1994. A postmodern philosophy of science? South African Journal of Philosophy 13/3, 153-159.

McMullin, E 1981. How should cosmology relate to theology?, in Peacocke, A R (ed), The sciences and theology in the twentieth century. Notre Dame: University of Notre Dame Press.

Midgley, M 1992. Science as salvation: A modern myth and its meaning. London: Routledge.

Moore, G 1994. A scene with Cranes: Engagement and truth in religion. Philosophical Investigations 17, 1-13.

Peacocke, A R 1990. Theology for a scientific age. Oxford: Basil Blackwell. 
Placher, W C 1989. Unapologetic theology: A Christian voice in a Christian conversation. Louisville: Westminster/John Knox.

Proudfoot, W 1985. Religious experience. Berkeley: University of California Press.

Rescher, N 1988. Rationality. Oxford: Clarendon Press. 1992. A system of pragmatic idealism, Vol 1. Princeton: Princeton University Press.

Rouse, J 1991. The politics of postmodern philosophy of science. Philosophy of Science 58, 607-627.

Stone, J 1992. The minimalist vision of transcendence: A naturalist philosophy of religion. New York: State University of New York Press.

Stoeger, W R 1988. Contemporary cosmology and its implications for the sciencereligion dialogue, in Russell, $\mathrm{R} J$, Stoeger, W R, George Koyne, S J (eds), Physics, philosophy and theology: A common quest for understanding, 219-248. Rome: Vatican Observatory.

Theissen, G 1984. Biblical faith: An evolutionary approach. London: SCM.

Trigg, R 1993. Rationality and science: Can science explain everything? Oxford: Blackwell.

Van Fraassen, B 1989. The scientific image. Oxford: Clarendon Press.

Van Huyssteen, J W 1989. Theology and the justification of faith: The construction of theories in Systematic Theology. Grand Rapids: Wm B Eerdmans.

1993. Critical realism and God: Can there be faith after foundationalism? in A Van Niekerk, A, Esterhuyse, W; Hattingh, J (eds), Intellektueel in konteks, 253266. Pretoria: HSRC Publishers. 